\title{
ОТРАСЛЕВАЯ ЭКОНОМИКА
}

DOI: $10.15838 /$ esc.2016.2.44.10

УДК 630.611, ББК 65.341.55

(C) Кун Фаньбинь, Фань Бинь, Чэнь Шэньдун

\section{Коллективное право на леса и его влияние на инвестиционную деятельность фермерских хозяйств и динамику товарной лесопродукции*}

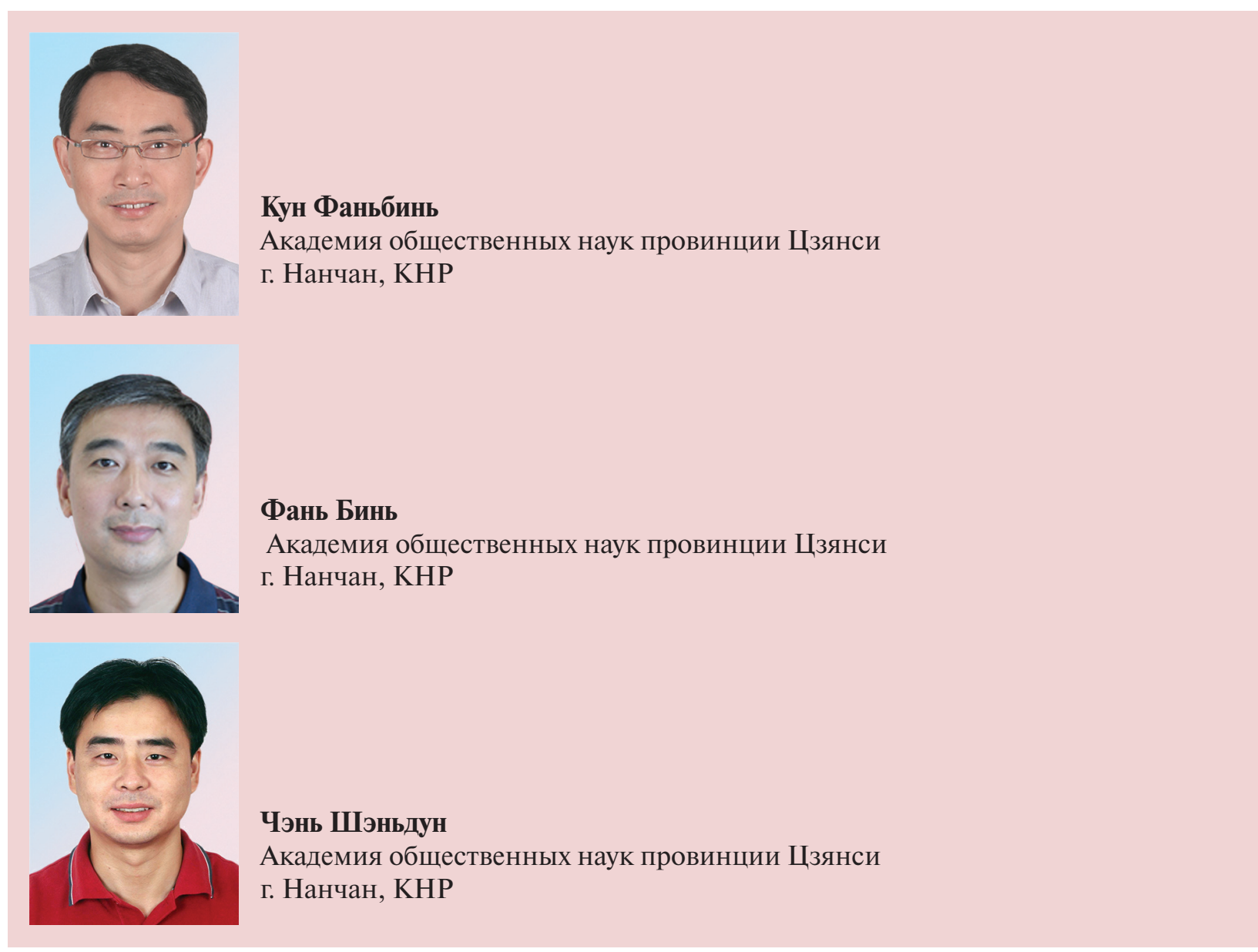

* Данное исследование проводится при поддержке Государственного фонда естественных наук Китая (National Natural Science Foundation of China) (№ 71173095; № 41261110; № 41161087) и Проекта кредитов Всемирного банка (World Bank Loan Project) (№ jxsczcqs2012-02). 
Аннотация. Цель данного исследования - определить взаимосвязь между фрагментированными коллективными лесными угодьями, инвестициями фермеров и объемом товарной продукции лесного хозяйства, изучить рациональность реформы права коллективного лесопользования после разрозненной эксплуатации лесных массивов. Исследование использует данные опроса 2420 фермеров в девяти провинциях Китая: Фуцзянь, Цзянси, Хунань, Сычуань, Чжэцзян, Гуанси, Хэнань, Шаньдун и Ляонин. Результаты показывают, что если используется S-индекс, то фрагментированность лесных массивов достигает 0,41 и провинции располагаются следующим образом (от более высокой до более низкой степени фрагментированности): Чжэцзян, Цзянси, Хунань, Ляонин, Сычуань, Фуцзянь, Гуанси и Шаньдун. При определенных интервалах фрагментированности (ее коэффициент ниже 0,22 или выше 0,51) чем выше фрагментированность лесного массива, тем меньше инвестиции в развитие фермерских хозяйств. Модель соотношения между капиталовложениями и выпуском продукции указывает на то, что лесное хозяйство отражает негативные последствия для производства продукции лесного комплекса, в то время как другие переменные, такие как труд, материальные затраты и размер лесных массивов, оказывают положительное воздействие. При производстве бамбука уровень фрагментированности имеет негативные последствия для лесных массивов и значительное позитивное влияние на используемый труд. Исследование предполагает, что, после того как земля распределена между домохозяйствами, физические инвестиции становятся ключевым фактором, влияющим на выпуск товарной продукции, и должны приниматься во внимание при проведении политики, направленной на повышение стимулирования фермеров. На основе этого исследования предложены рекомендации в отношении политики в сфере эксплуатации в крупных масштабах лесных массивов.

Ключевые слова: реформа права коллективного лесопользования; фрагментированные лесные массивы; инвестиции фермеров; выпуск продукции лесного хозяйства.

\section{1. Введение}

Фрагментация лесных массивов - это процесс, включающий изменения в таких аспектах, как география, население, семейные традиции и управление. Китай обладает разнообразием ландшафтов, что обеспечивает выгодные условия для использования лесных массивов и в то же время вызывает их фрагментацию. С исторической точки зрения население Китая резко увеличилось, начиная с династии Сун, и имеющиеся земли не успевают удовлетворять потребности всё возрастающего населения. Это одна из причин увеличения фрагментированности лесных массивов. Она выросла за счет традиционной системы наследования, согласно которой земля делится между детьми. С точки зрения механизма изменения лесного права лесные угодья становились все более раздробленными из-за политики 1980-х годов и коллективного лесного права, принятого в 2003 году. Для того чтобы преодолеть экономические проблемы, возникшие в результате деятельности малого бизнеса, в 2008 году правительство выдвинуло ряд мер. Некоторые ученые утверждают, что фрагментированность лесных массивов не будет способствовать повышению эффективности их эксплуатации, а другие говорят о том, что фрагментированность является лишь частью китайской традиции, потому что это справедливо, когда каждый фермер имеет собственный участок земли. С эмпирической точки зрения фрагментация лесных массивов существенно не изменилась, хотя нынешняя политика реформирования права коллективного лесопользования 
предоставляет фермерам право торговли. На сегодняшний день имеется недостаточно исследований о крупномасштабной оценке фрагментированности лесов, вкладе фермеров в производство продукции лесного хозяйства при такой политике. В исследовании используются данные опроса 2420 домохозяйств в 18 уездах провинций Фуцзянь, Цзянси, Хунань, Сычуань, Чжэцзян, Гуанси, Хэнань, Шаньдун и Ляонин, проведенного с целью выявления взаимосвязи между фрагментированными коллективными лесными массивами, инвестициями в развитие фермерских хозяйств и выпуском продукции лесного хозяйства, а также для того, чтобы исследовать рациональность реформирования права коллективного лесопользования после разрозненной эксплуатации лесных массивов.

\section{1. Три основные стадии процесса фраг-} ментации лесов

В Китае процесс фрагментации лесов и реформа права коллективного лесопользования проходят вместе, а фрагментированность лесных массивов встречается в основном в южных лесных районах. Процесс фрагментации может быть разделен на три этапа. Первый этап происходил в 1980-х гг., когда был издан официальный документ, объявивший, что лесное право необходимо стабилизировать (закрепить право пользования лесом), поврежденные земли восстановить и определить ответственность за пользование лесными ресурсами, что также ускоряет скорость процесса фрагментации лесов. Статистические данные Департамента лесного комплекса показывают, что до 1984 года 90\% владельцев лесных угодий среди перечисленных 9 провинций имели по 0,43 га в среднем и площадь на душу населения составляла 0,04 га. Количество фермеров, живущих в лесах, и количество коллективных лесных хозяйств увеличились более чем на 400 единиц (Lu, 2002). Исследование, проведенное Di в 1994 году, описывает процесс передачи коллективного права на леса фермерским хозяйствам. Второй этап проходил с конца 1980-х до 1990-х годов, когда происходила продажа лесных угодий. Lu (2004) считает, что такая продажа поможет решить существующие проблемы, такие как низкая эффективность распределения и малые масштабы, связанные с существующей системой управления землями. Путем продажи коллективные леса переходят в собственность фермеров, что увеличивает масштабы лесопользования. Однако это не решает проблему фрагментированности лесных массивов. Третий и последний этап - это верификация права собственности на лесные угодья. В 2003 году провинция Фуцзянь провела реформу права коллективного лесопользования (далее - Лесная реформа), включая разъяснение принципов владения, повышение эффективности использования, наделение правом распоряжения и защиту прав выгодоприобретателя после того, как Государственный совет объявил о «решении ускорить развитие лесного хозяйства». Позже провинции Цзянси, Ляонин и Чжэцзян также провели такую реформу. В июне 2008 года появился еще один официальный документ, который четко определил основной объект работы лесного хозяйства. До конца 2009 года была подтверждена собственность на более чем 100 млн. га леса, что составляет 59,4\% общей площади коллективных лесов. Площадь сертифицированных лесов составляет более 80 млн. га, или около $75 \%$ общего количества проверенных лесов (Jia, 2009). Лесная реформа способствует диверсификации собственности и пользования лесами и ускоряет процесс их фрагментации (Kong, 2008). 
1.2. Проблемы, стоящие перед лесопользователями после фрагментации лесных массивов

Исследуя негативные последствия фрагментации лесов, многие ученые критикуют эту ситуацию и эксплуатацию небольших участков лесов с точки зрения масштабов использования. Например, некоторые ученые (Song и др., 1997) предполагают, что система домохозяйств в коллективном использовании лесов в Китае может оказаться полезной при распределении лесных массивов. Li (2001) предполагает, что улучшить бедственное положение в лесном хозяйстве можно с помощью коллективного лесного права. Wan (2009) отмечает, что неотложной задачей становится ускорение сотрудничества для решения проблемы фрагментированности лесов. По мнению китайских фермеров, владение лесом является одной из форм их личного имущества (в отличие от того, как если бы они пользовались государственным лесом в рабочем процессе), а такого рода использование в микробизнесе приводит к ослаблению конкуренции в связи с эффектами масштабирования ( $\mathrm{Li}$ and Wang, 2003; Liu, 2000). Zeng (2009) указывает, что система эксплуатации леса домохозяйствами увеличивает риски ожидаемой доходности, краткосрочные спекуляции и монополию на земельные ресурсы, a Luo и Li (1999) представляют доказательства таких рисков в провинциях Сычуань и Гуандун. Однако существуют противоположные мнения. Gao (2007) считает, что текущее социальное положение в Китае не благоприятствует этому, т.к. живущие в лесах фермеры гораздо охотнее вкладывают труд и капитал в повышение продуктивности лесов, поскольку обладают всеми преимуществами. Заинтересованность приносит более высокую прибыль. Она предполагает, что результат не действителен, если он не может пройти анализ затрат и выгод, и, вследствие того что лесное хозяйство не требует высоких технологий, люди вполне могут управлять своими собственными участками леса.

2. Эмпирическое исследование связи между фрагментированными коллективными лесными угодьями, инвестициями фермеров и производством продукции лесного хозяйства

2.1. Сущность процесса фрагментации лесных массивов и количественный метод выделения

2.1.1. Определение фрагментированности лесного массива

Понятие фрагментированности земель широко используется в Китае. Фрагментированность лесов основана на фрагментированности земель, но не имеет точного определения. Таким образом, данное исследование требует более четкого определения фрагментированности пахотных земель для определения фрагментированности лесов. Фрагментированность лесов имеет два необходимых условия: наличие более двух участков леса и их небольшую площадь. Исходя из этих условий фрагментированность лесов означает, что фермер должен обрабатывать два и более небольших участка леса, которые не являются смежными. В данном исследовании мы ориентируемся на экономический анализ прилегающих лесов, хотя существует возможность поменять далекие друг от друга участки леса на смежные друг с другом и на бо́льшие по площади. Мы также подчеркиваем возможность экономической выгоды от использования небольших участков и экономию за счёт роста масштаба производства, который заключается в повышении отдачи от ресурсов, увеличении доходов и уменьшении расходов (Zhang и Huang, 1997; Cheng, 2001). 
Основываясь на этом определении, можно сказать, что фрагментированность лесов больше учитывает экономическую сторону и, следовательно, должна обладать следующими двумя характеристиками: (1) участок слишком мал, чтобы получить экономию за счёт роста масштаба производства и (2) участки могут быть объединены путем продажи.

2.1.2. Измерение фрагментированности лесных массивов

Существует два основных метода для измерения фрагментированности лесных массивов. Первый - использование единого индекса для измерения уровня фрагментированности исходя из количества и площади участков (Binns, 1950), второй построение более сложного индекса. King и Burton (1982) разработали $S$-индекс, $J$-индекс и $I$-индекс на основе шести факторов, включающих размер фермы, количество участков, размер участка, форму участка, пространственное размещение участка, вид культуры.

Эти показатели выражаются следующим образом:

$$
\begin{gathered}
S=1-\frac{\sum_{i=1}^{n} \alpha_{i}^{2}}{\left(\sum_{i=1}^{n} \alpha_{i}\right)^{2}}, \\
J=\frac{\sqrt{\sum_{i=1}^{n} \alpha_{i}}}{\sum_{i=1}^{n} \sqrt{\alpha_{i}}}, \\
I=\frac{\left(\sum_{i=1}^{n} \alpha_{i}\right) / n}{100} \times \sum W,
\end{gathered}
$$

где $n$ - количество участков, принадлежащих фермеру, $\alpha$ - размер участка, а $W$ - расстояние между участками.
Значения $S$ и $J$ находятся в диапазоне между 0 и 1 . Когда $S$ ближе к 1 , то уровень фрагментированности лесов выше, а $J$-индекс имеет противоположное значение. Все три индекса используют количество участков и их размеры в качестве важных факторов, но мы не можем определить, который из них имеет более важное значение. Кроме того, $J$-индекс не может показывать, что уровень фрагментированности лесных массивов должен уменьшаться, если площадь более крупных участков увеличивается, а площадь небольших участков уменьшается.

Каждый метод имеет свои преимущества и недостатки. В данном исследовании мы ориентируемся на количество и размеры участков и на расстояние между участком и домом фермера. Однако для того, чтобы обеспечить лучшее измерение уровня фрагментированности лесных массивов, мы также используем $S$-индекс как дополнительный.

\section{2. Количественный анализ уровня фраг-} ментированности лесов

2.2.1. Статистическая характеристика ситуации до и после Лесной реформы

Таблица 1 показывает количество участков и изменения в ситуации с лесными участками, предоставленными фермерам, до и после проведения Лесной реформы. Размер среднестатистического участка во владении фермера увеличился на 0,92 , что на $16,12 \%$ больше, чем до реформы. В исследуемых районах количество участков, принадлежащих фермерам, увеличилось больше всего в провинциях Гуанси и Ляонин и меньше всего - в провинции Хунань. 
Таблица 1. Изменение числа фермерских участков леса до и после Лесной рефрормы

\begin{tabular}{|l|c|c|c|c|c|c|c|c|c|c|}
\hline $\begin{array}{c}\text { Количество } \\
\text { участков }\end{array}$ & Фуцзянь & Гуанси & Хэнаннь & Ляонин & Шаньдун & Сычуань & Чжецзян & Цзянси & Хунань & $\begin{array}{c}\text { Среднее } \\
\text { значение }\end{array}$ \\
\hline $\begin{array}{l}\text { Количество } \\
\text { участков до } \\
\text { рефрормы }\end{array}$ & 1,83 & 2,13 & 1,38 & 2,25 & 1,13 & 6,31 & 4,06 & 3,87 & 3,02 & 3,35 \\
\hline $\begin{array}{l}\text { Количество } \\
\text { участков после } \\
\text { реформы }\end{array}$ & 2,07 & 2,61 & 1,56 & 2,89 & 1,22 & 7,33 & 4,42 & 4,55 & 3,12 & 3,89 \\
\hline $\begin{array}{l}\text { Динамика } \\
\text { количества } \\
\text { участков }\end{array}$ & 0,24 & 0,48 & 0,18 & 0,64 & 0,09 & 1,02 & 0,36 & 0,68 & 0,10 & 0,54 \\
\hline $\begin{array}{l}\text { Коэфффициент } \\
\text { изменения, \% }\end{array}$ & 13,11 & 22,54 & 13,04 & 28,44 & 7,97 & 16,09 & 8,87 & 17,57 & 3,31 & 16,12 \\
\hline
\end{tabular}

Из приведенных данных мы видим, что проблема фрагментированности лесов действительно существует и лесная реформа может сделать ее еще серьезнее.

2.2.2. Анализ уровня фрагментированности лесов на основе опроса 2420 фермерских хозяйств

Как показали данные опроса, 36,47\% фермеров эксплуатируют по 1-2 лесных участка; 27,98\% фермеров - 3-4; 16,87\% - 5-6; $13,01 \%$ - 7-10 и 5,66\% - более 10 лесных участков (табл. 2). В среднем каждый фермер имеет 4,52 лесных участка. На основании статистических результатов выявлено, что самое большое количество лесных участков, которыми владеют фермеры, находится в провинциях Цзянси, Чжэцзян и Сычуань, а наименьшее количество - в провинции Шаньдун. Разница определяется в основном особенностями ландшафта и временем проведения Лесной реформы.

Таблииа 3 показывает число участков леса, эксплуатируемых фермерами. В провинции Шаньдун на одно домохозяйство приходится в среднем 9,062 га и средняя площадь лесных участков в провинции составляет 7,487 га. В других провинциях фермеры работают на участках площадью в среднем 2,5 га, а площадь одного участка превышает 0,66 га. С точки зрения масштабов эксплуатации 75\% фермеров работают на участках площадью 1,33-3,33 га, а 7,85\% фермеров - на участках площадью менее 0,1 га. Данные результаты показывают, что после Лесной реформы более очевидным становится изменение масштабов эксплуатации и размер участка является стабильным. По сравнению с пахотными землями фрагментированность лесных массивов несущественна.

Таблицы 4 и 5 показывают распределение фермерских лесных участков в различных масштабах и распределение соотношения расстояния между лесным участком и дорогой. В целом расстояние между лесным участком и дорогой должно влиять на эффективность производства, поскольку чем больше расстояние, тем больше

Таблица 2. Количество лесных участков, управляемых фрермерами

\begin{tabular}{|c|c|c|c|c|c|c|c|}
\hline $\begin{array}{c}\text { Количество } \\
\text { домохозяйств, } \\
\text { участвующих } \\
\text { в исследовании }\end{array}$ & $\begin{array}{c}\text { Среднее } \\
\text { количество } \\
\text { участков леса } \\
\text { на домохозяйство }\end{array}$ & $\begin{array}{c}\text { Эксплуатация } \\
12 \text { участков } \\
\text { леса, \% }\end{array}$ & $\begin{array}{c}\text { Эксплуатация } \\
3 \sim 4 \text { участков } \\
\text { леса, \% }\end{array}$ & $\begin{array}{c}\text { Эксплуатация } \\
5 \sim \text { участков } \\
\text { леса, } \%\end{array}$ & $\begin{array}{c}\text { Эксплуатация } 10 \text { участков } \\
\text { леса, } \%\end{array}$ & $\begin{array}{c}\text { Эксплуатация } \\
10 \text { и более } \\
\text { участков } \\
\text { леса, } \%\end{array}$ & $\begin{array}{c}\text { Эксплуатация } \\
20 \text { и более } \\
\text { участков леса, } \\
\%\end{array}$ \\
\hline 2420 & 4,52 & 36,47 & 27,98 & 16,87 & 13,01 & 4,48 & $1,18 \%$ \\
\hline 263 & 3 & 50,83 & 31,40 & 9,92 & 7,85 & - & - \\
\hline
\end{tabular}


Таблица 3. Список лесных участков в целом по стране и в исследуемых провинциях

\begin{tabular}{|c|c|c|c|c|c|}
\hline Провинция & $\begin{array}{c}\text { Среднее количество } \\
\text { лесных участков } \\
\text { на домохозяйство, } \\
\text { участков }\end{array}$ & $\begin{array}{c}\text { Средняя площадь } \\
\text { на домохозяйство, га }\end{array}$ & $\begin{array}{c}\text { Средняя площадь } \\
\text { лесного участка, га }\end{array}$ & $\begin{array}{c}\text { Максимальная } \\
\text { площадь лесного } \\
\text { участка, га }\end{array}$ & $\begin{array}{c}\text { Минимальная } \\
\text { площадь лесного } \\
\text { участка, га }\end{array}$ \\
\hline Шаньдун & 1,220 & 9,062 & 7,487 & 46,667 & 0,013 \\
\hline Ляонин & 2,890 & 5,307 & 1,837 & 20,000 & 0,133 \\
\hline Хэнань & 1,560 & 0,788 & 0,507 & 5,533 & 0,004 \\
\hline Сычуань & 7,330 & 2,549 & 0,676 & 8,333 & 0,003 \\
\hline Чжэцзян & 4,420 & 4,397 & 0,996 & 7,400 & 0,033 \\
\hline Фуцзянь & 2,070 & 5,193 & 2,507 & 21,667 & 0,107 \\
\hline Хунань & 3,120 & 2,665 & 0,854 & 12,000 & 0,033 \\
\hline Цзяньси & 4,550 & 11,425 & 2,512 & 107,813 & 0,013 \\
\hline Гуанси & 2,610 & 2,519 & 0,967 & 10,667 & 0,007 \\
\hline
\end{tabular}

Таблица 4. Распределение фермерских лесных участков в различных масштабах

\begin{tabular}{|l|c|c|c|c|c|c|}
\hline \multicolumn{1}{|c|}{ Диапазон, га } & $<1$ & $20-40$ & $40-50$ & $50-60$ & $60-100$ & $>100$ \\
\hline $\begin{array}{l}\text { Доля средней площади } \\
\text { на лесной участок, \% }\end{array}$ & 13,73 & 61,54 & 13,46 & 4,4 & 3,3 & 3,57 \\
\hline $\begin{array}{l}\text { Доля средней площади } \\
\text { на домохозяйство, \% }\end{array}$ & 7,85 & 40,9 & 13,64 & 7,85 & 11,16 & 18,6 \\
\hline
\end{tabular}

Таблица 5. Распределение соотношения расстояния между лесным участком и дорогой

\begin{tabular}{|c|c|c|c|c|c|c|c|c|}
\hline Диапазон, м & $<100$ & $100-500$ & $500-1000$ & $1000-2000$ & $2000-3000$ & $3000-4000$ & $4000-5000$ & $>5000$ \\
\hline Доля, \% & 9,22 & 24,25 & 22,24 & 20,64 & 11,82 & 3,81 & 2,41 & 5,61 \\
\hline
\end{tabular}

Таблица 6. Степень фррагментированности лесных земель в целом по стране и в разных провинциях

\begin{tabular}{|l|c|c|c|c|c|c|c|c|c|c|}
\hline Регион & Китай & Шаньдун & Ляонин & Хэнань & Сычуань & Чжецзян & Фуцзянь & Хунань & Цзянси & Гуанси \\
\hline S-индекс & 0.41 & 0.11 & 0.46 & 0.16 & 0.42 & 0.62 & 0.42 & 0.48 & 0.58 & 0.40 \\
\hline
\end{tabular}

времени требуется для транспортировки товаров. Самое большое расстояние, указанное в опросе, составляет 16 км, длина $5,61 \%$ участков превышает 5 км, а длина $9,22 \%$ участков менее 0,1 км. Расстояние между лесным участком и дорогой менее $0,5 \mathrm{KM}$.

Комплексный $S$-индекс характеризует уровень фрагментированности лесов. В данном исследовании количество и площадь лесных участков и расстояние от участка до дороги увеличивает измерение $S$-индекса.

Судя по данным таблицы 6, уровень фрагментированности лесов Китая составляет $0,41 . S$-индекс является самым высо- ким в провинции Чжэцзян, за ней следуют провинции Цзянси, Хунань, Ляонин и Сычуань. S-индекс в провинции Шаньдун - самый низкий. Исследуемые провинции (Цзянси, Фуцзянь, Чжэцзян и Ляонин) имеют высокий уровень фрагментированности лесов. Это показывает, что Лесная реформа влияет на их фрагментированность. Кроме того, уровень фрагментированности лесных массивов напрямую связан с естественной географией, т.К. результаты свидетельствуют о значительно более высоком уровне фрагментированности лесных массивов в горной местности, чем на равнине. Провинция Сычуань является примером этого. 
2.3. Описание инвестиций фермеров при фрагментированности лесных массивов

Приведенные в таблиие 7 результаты показывают, что средний объем инвестиций фермеров в лесное хозяйство составляет менее 2200 юаней, но растет год от года. Провинции Хэнань, Шаньдун и Чжэцзян имеют относительно большие инвестиции за счет потребности в сырье (фрукты являются основным продуктом в этих провинциях). В провинциях Гуанси, Хунань, Сычуань и Цзянси объем инвестиций меньше, потому что главным продуктом является древесина.

Как видно из таблицы 8 , средний размер инвестиций фермеров ниже, чем общий доход их домохозяйств. Обычно это соотношение составляет менее 0,06 . Иными словами, фермеры получают небольшой доход от эксплуатации лесного хозяйства вследствие низкого уровня инвестиций. Таким образом, лесное хозяйство играет не очень важную роль в доходах домохозяйств. В целом соотношение между инвестициями и доходом в провинциях Гуанси, Хунань и Цзянси составляет менее 0,03 .

\section{4. Взаимосвязь между инвестициями} фермеров и фрагментированностью лесных массивов

2.4.1. Взаимосвязь между объемом инвестиций фермеров и уровнем фрагментированности лесов

В целях изучения взаимосвязи между инвестициями фермеров и уровнем фрагментированности лесов мы используем уровень фрагментированности лесов в качестве независимой переменной $(X)$, а инвестиции домохозяйств - в качестве зависимой переменной (IN) для построения одномерной регрессионной модели. Выборки показывают нелинейную зависимость ( $S$-образная форма), и, таким образом, модель строится по следующей формуле:

$$
\begin{gathered}
I N=-10831,68+181454,30 X- \\
-586913,73 X^{2}+530794,33 X^{3},
\end{gathered}
$$

где $t$ равно -3,742 для пересечения, 5,485 для $X,-5,991$ для $X^{2}$ и $6,249 X^{3}, R^{2}$ равно 0,705 и значение $F$ равно 28,668 .

Из уравнения (4) мы видим, что $R^{2}$ равно 0,705 и, следовательно, модель обладает высокой наглядностью. Значение Р посто-

Таблица 7. Инвестиции фрермерских домохозяйств в лесное хозяйство в 9 провинциях (регионах)

\begin{tabular}{|c|c|c|c|c|c|c|c|c|c|c|}
\hline Год & $\begin{array}{c}\text { Фуцзянь, } \\
\text { юаней }\end{array}$ & $\begin{array}{c}\text { Гуанси, } \\
\text { юаней }\end{array}$ & $\begin{array}{c}\text { Хэнаннь, } \\
\text { юаней }\end{array}$ & $\begin{array}{c}\text { Ляонин, } \\
\text { юаней }\end{array}$ & $\begin{array}{c}\text { Шаньдун, } \\
\text { юаней }\end{array}$ & $\begin{array}{c}\text { Сычуань, } \\
\text { юаней }\end{array}$ & $\begin{array}{c}\text { Чжецзян, } \\
\text { юаней }\end{array}$ & $\begin{array}{c}\text { Цзянси, } \\
\text { юаней }\end{array}$ & $\begin{array}{c}\text { Хунань, } \\
\text { юаней }\end{array}$ & $\begin{array}{c}\text { В среднем, } \\
\text { юаней }\end{array}$ \\
\hline 2003 & 611,8 & 107,74 & 4995,2 & 384,7 & 1452,51 & 565,5 & 1430,34 & 391,94 & 73,72 & 1112,61 \\
\hline 2007 & 983,8 & 122,23 & 6152,1 & 1702,83 & 1866,48 & 735,49 & 2089,43 & 616,51 & 214,52 & 1609,27 \\
\hline 2008 & 945,2 & 152,53 & 6972,5 & 1670,93 & 2145,77 & 737,56 & 2228,55 & 902,89 & 431,23 & 1789,57 \\
\hline 2009 & 1353 & 184,96 & 8188,5 & 1814,06 & 2297,92 & 925,17 & 2969,84 & 1027,39 & 639,96 & 2155,64 \\
\hline
\end{tabular}

Таблица 8. Соотношение инвестиций в лесное хозяйство и общего дохода фрермерской семьи

\begin{tabular}{|c|c|c|c|c|c|c|c|c|c|c|}
\hline Год & $\begin{array}{c}\text { Фуцзянь, } \\
\%\end{array}$ & $\begin{array}{c}\text { Гуанси, } \\
\%\end{array}$ & $\begin{array}{c}\text { Хэнаннь, } \\
\%\end{array}$ & $\begin{array}{c}\text { Ляонин, } \\
\%\end{array}$ & $\begin{array}{c}\text { Шаньдун, } \\
\%\end{array}$ & $\begin{array}{c}\text { Сычуань, } \\
\%\end{array}$ & $\begin{array}{c}\text { Чжецзян, } \\
\%\end{array}$ & $\begin{array}{c}\text { Цзянси, } \\
\%\end{array}$ & $\begin{array}{c}\text { Хунань, } \\
\%\end{array}$ & $\begin{array}{c}\text { В среднем, } \\
\%\end{array}$ \\
\hline 2003 & 3,2 & 1,1 & 15,1 & 2,6 & 12,3 & 4,8 & 4,9 & 2,0 & 0,6 & 6,6 \\
\hline 2007 & 3,5 & 0,8 & 13,6 & 5,9 & 10,8 & 3,6 & 4,5 & 2,0 & 1,0 & 6,1 \\
\hline 2008 & 2,8 & 0,9 & 14,4 & 4,9 & 11,4 & 3,5 & 4,1 & 3,0 & 1,8 & 6,2 \\
\hline 2009 & 3,5 & 0,9 & 14,9 & 4,7 & 9,2 & 3,6 & 5,0 & 2,9 & 2,5 & 6,1 \\
\hline
\end{tabular}


янной и независимой переменной равно 0 , а это означает, что когда другие переменные остаются постоянными, независимая переменная X не оказывает сильного воздействия на уровень фрагментированности лесов и объем фермерских инвестиций. Получение предельного значения из этого уравнения, когда уровень фрагментированности лесов находится между 0,22 и 0,51, способствует тому, что этот показатель возрастает, и, когда Х находится вне этого диапазона, уровень фрагментированности лесов меньше и подходит для инвестиций домашних хозяйств.

2.4.2. Взаимосвязь между уровнем фрагментированности лесов и соотношением между инвестициями и доходами

Для того чтобы проанализировать взаимосвязь между уровнем фрагментированности лесов и соотношением между инвестициями и доходами, воспользуемся той же независимой переменной и отношением инвестиций и доходов $(Y I)$ в качестве зависимой переменной для построения одномерной регрессионной модели. Модель может быть выражена следующим образом:

$$
Y I=164,082 X-620,435 X^{2}+592,516 X^{3},
$$

где $T$ равно 2,814 для $X,-3,593$ - для $X^{2}$ и 3,958 - для $X^{3} . R^{2}$ равно 0,821 и значение $F$ равно 55,154 .

Из уравнения (5) мы видим, что $R^{2}$ равно 0,821 и, таким образом, модель обладает высокой наглядностью. Значение $Р$ постоянной и независимой переменной составляет менее 0,01 , а это значит, что при других равных условиях независимая переменная $X$ оказывает значительное влияние на уровень фрагментированности лесов и соотношение между инвестициями и доходами фермеров. Если получается предельное значение из этого уравнения, когда уровень фрагментированности лесов составляет от 0,17 до 0,52, это указывает на то, что этот показатель выше, а когда X находится вне этого диапазона, уровень фрагментированности лесов меньше, что подходит для инвестиций домашних хозяйств.

\section{5. Влияние фрагментированности лес-} ных массивов и фермерских инвестиций на лесохозяйственное производство

\subsection{1. Выбор переменных для модели}

Это исследование использует функцию Кобба-Дугласа для изучения взаимосвязи между фрагментированностью лесов и лесохозяйственным производством. Поскольку исследование направлено на изучение влияния фрагментированности лесных массивов и фермерских инвестиций на лесохозяйственное производство, количество участков леса является независимой переменной, а лесохозяйственное производство на одном участке - зависимой переменной. Производственная функция означает, что при определенном технологическом уровне фиксированный объем инвестиций опирается на возможности производства. Инвестиции включают труд, капитал и землю. В данном исследовании независимые переменные определены и объяснены следующим образом:

(1) инвестиции в трудовые ресурсы (LDTR): стандартное рабочее время (день);

(2) прочие инвестиции (WZTR): в том числе семена, химические вещества, питательные вещества и прочие затраты;

(3) площадь лесного участка (LDMJ): площадь эксплуатируемых лесных массивов;

(4) уровень фрагментированности лесов (LDXSCD): количество участков леса на домохозяйство. 


\subsection{2. Построение модели}

Производственная функция КоббаДугласа может быть выражена как

$$
Y=\alpha_{0} x_{1^{1}}^{\beta} x_{2^{2}}^{\beta},
$$

где $Y$ - производство, $X_{i}-i$-ый ввод.

Количество лесных участков, находящихся в эксплуатации, показывает изменение фрагментированности лесных массивов и, следовательно, не может быть использовано в качестве одной входной переменной. На основании теории развития экономики и прошлого опыта масштабы эксплуатации определяются прежде всего фрагментированностью лесных массивов. Поскольку $\beta_{i}(i=1,2 \ldots k)$ - это эластичность, мы строим модель, которая связывает ее с фрагментированностью леса:

$$
\beta_{i}=\alpha_{i}+\gamma_{i}^{L n P}, i=1,2 \ldots k .
$$

$P$ в уравнении (7) обозначает количество участков леса. Подставив $P$ в производственную функцию Кобба-Дугласа, мы можем получить:

$$
\begin{gathered}
Y=\alpha_{0} x_{1}^{\left(\alpha_{1}+\gamma_{i} \times L n P\right)} \times \\
\times x_{2}^{\left(\alpha_{2}+\gamma_{2} \times L n P\right)} \times x_{k}^{\left(\alpha_{k}+\gamma_{k} \times L n P\right)} .
\end{gathered}
$$

Подставив натуральный логарифм в обе стороны, мы получаем модель II, которая выражается следующим образом:

$$
\begin{aligned}
& \operatorname{Ln} Y=\operatorname{Ln} \alpha_{0}+\left(\alpha_{1}+\gamma_{1} \operatorname{Ln} P\right) \operatorname{Ln} X_{1}+ \\
& +\left(\alpha_{2}+\gamma_{2} \operatorname{Ln} P\right) \operatorname{Ln} X_{2} \\
& +\cdots \cdots+\left(\alpha_{k}+\gamma_{k} \operatorname{Ln} P\right) \operatorname{Ln} X_{k} \\
& =\operatorname{Ln} \alpha_{0}+\sum \alpha_{1} \operatorname{Ln} X_{i}+\sum \gamma_{1} \operatorname{Ln} P \operatorname{Ln} X_{i}
\end{aligned}
$$

Из уравнения (8) следует, что шкала эластичности $V$ может быть выражена следующим образом:

$$
\begin{aligned}
V=\sum \beta_{1} & =\sum\left(\partial_{1}+\gamma_{i} \operatorname{Ln} P\right)=\sum \alpha_{i+} \operatorname{Ln} P \sum \gamma_{i}= \\
& =\gamma_{0} \operatorname{Ln} P+\sum \alpha_{i}, \text { where } \gamma_{0}=\sum \gamma_{i} .
\end{aligned}
$$

Модель II является расширением производственной функции Кобба-Дугласа и может быть использована для изучения воздействия фрагментированности лесов на экономию за счёт роста масштаба производства. Переменная $P$ должна быть целым положительным числом. Если фрагментированности лесов нет $(P=1)$, то она возвращается к стандартной функции Кобба-Дугласа.

Существуют две потенциальные проблемы в модели II. Первая проблема заключается в том, что новая переменная $\operatorname{Ln} P \operatorname{Ln} X_{i}$ или $P \operatorname{Ln} X_{i}$ может быть мультилинейной, а вторая проблема в том, что это свойство в стандартной производственной функции Кобба-Дугласа не может быть сохранено. Один из способов решения этой проблемы - добавить одно ограничение в то, что все $\gamma_{i}$ равны. То есть:

$$
\gamma_{1}=\gamma_{2}=\ldots=\gamma_{k}=\gamma \text {. }
$$

Таким образом, мы можем получить модель III:

$\operatorname{Ln} Y=\operatorname{Ln} \alpha_{0}+\sum \alpha_{i} \operatorname{Ln} \chi_{i}+\kappa \gamma\left(\operatorname{Ln} P \sum \operatorname{Ln} \chi_{i}\right)$.

Коэффициент, соответствующий экономии за счёт роста масштаба производства, определяется по формуле: $\sum \alpha_{i}+k \gamma L n P$ (при функции линейного масштаба он определяется по формуле: $\left.\sum \alpha_{i}+k \gamma P\right)$. Поэтому, если мы находим, что $\sum \gamma_{1}$ или $\gamma$ меньше 0 , то фрагментированность лесов оказывает негативное воздействие на экономию за счёт роста масштаба производства и на лесохозяйственное производство. Выбор функции масштаба (линейная или полулогарифмическая) зависит от значения $R^{2}$ и вероятности.

2.4.3. Результаты оценки моделей

\section{(1) Описание переменных}

Данные, использованные в настоящем эмпирическом исследовании, были получены в 2009 году в ходе опроса крестьян из девяти провинций. Товары лесного хозяй- 
ства включают следующие: древесина, бамбук, побеги бамбука, экономический лесной продукт 1, экономический лесной продукт 2, экономический лесной продукт 3 , древесное топливо и недревесные продукты леса. Выход рассчитывается на основе домохозяйств, площадь участков определяется в гектарах, физические инвестиции - в долларах, труд - в рабочих днях. Исходя из полученных данных основными продуктами являются дерево и бамбук, а другие находятся в относительно небольшом количестве.

\section{(2) Соответствие и выбор модели}

Прежде чем провести оценку модели, мы проанализируем функцию правдоподобия и $R^{2}$ (соответствие образцов и линии регрессии) с целью выбора модели. Результаты отбора показывают, что побеги бамбука, экономический лесной продукт 1, экономический лесной продукт 2 и экономический лесной продукт 3 должны быть линейными в модели. При использовании $R^{2}$ значение вероятности выше для экономической лесной продукции, а для других видов - низкое (табл. 9).

\section{(3) Выбор модели}

Из таблищы 10 мы видим, что, когда выходной продукцией является древесина, только LDXSCD имеет негативное влияние среди четырех независимых переменных, что соответствует нашим ожиданиям. Другие переменные, такие как труд, земля и капитал, имеют положительное влияние на выход лесной продукции. Значение $T$ соответствующей $\gamma$ физических инвестиций больше, чем 2, что указывает на значительное положительное влияние физических инвестиций. Однако $\gamma$ фрагментированности лесных массивов показывает значительное негативное влияние фрагментированности лесов. Предполагаемый результат в отношении бамбука отличается от наших ожиданий, где LDXSCD не оказывает негативного воздействия на лесохозяйственное производство, LDMJ оказывает негативное, а труд - позитивное влияние. По коэффициенту площади лесов мы видим, что негативное влияние территорий, на которых произрастает бамбук, является значительным.

Таблица 9. Результаты выбора модели

\begin{tabular}{|c|c|c|c|}
\hline $\begin{array}{c}\text { Сельскохозяйственные } \\
\text { культуры }\end{array}$ & Функция масштаба & Применимость $R^{2}$ & $\begin{array}{c}\text { Окончательно выбранная } \\
\text { модель }\end{array}$ \\
\hline \multirow{2}{*}{ Древесина } & Линейная модель & 0.135342 & \\
\hline & Логарифмическая модель & 0.267122 & Логарифмическая модель \\
\hline \multirow{2}{*}{ Бамбук } & Линейная модель & 0.025012 & \\
\hline & Логарифмиическая модель & 0.036994 & Логарифмическая модель \\
\hline \multirow{2}{*}{ Побеги бамбука } & Линейная модель & 0.676175 & \\
\hline & Логарифмическая модель & 0.269619 & Линейная модель \\
\hline \multirow{2}{*}{ Экономический лесной продукт 1} & Линейная модель & 0.066245 & \\
\hline & Логарифммическая модель & 0.095661 & Логарифмическая модель \\
\hline \multirow{2}{*}{ Экономический лесной продукт 2} & Линейная модель & 0.875314 & \\
\hline & Логарифмическая модель & Не применима & Линейная модель \\
\hline \multirow{2}{*}{ Экономический лесной продукт 3} & Линейная модель & 0.735718 & \\
\hline & Логарифмическая модель & 0.667665 & Линейная модель \\
\hline \multirow{2}{*}{ Древесное топливо } & Линейная модель & & \\
\hline & Логарифрмическая модель & 0.057076 & Логарифмическая модель \\
\hline \multirow{2}{*}{ Недревесные продукты леса } & Линейная модель & Не применима & Не применима \\
\hline & Логарифмическая модель & Не применима & \\
\hline
\end{tabular}


Таблица 10. Основные показатели по древесине, бамбуку, модель оценки

\begin{tabular}{|l|c|c|c|c|c|c|}
\hline \multirow{2}{*}{$\begin{array}{c}\text { Независимая } \\
\text { переменная }\end{array}$} & \multicolumn{5}{|c|}{ Древесина } \\
\cline { 2 - 7 } & $\begin{array}{c}\text { Коэфроцциент } \\
\gamma\end{array}$ & Значение $t$ & Значение $p$ & $\begin{array}{c}\text { Коэффрициент } \\
\gamma\end{array}$ & Значение $t$ & 3начение $p$ \\
\hline LDTR & 0,209085 & 1,624927 & 0,1069 & 0,247387 & 1,830346 & 0,0686 \\
\hline WZTR & 0,316939 & 4,187608 & 0,0001 & 0,002072 & 0,022804 & 0,9818 \\
\hline LDMJ & 0,219486 & 1,952609 & 0,0533 & $-0,19599$ & $-2,17862$ & 0,0305 \\
\hline LDXSCD & $-0,33482$ & $-2,9077$ & 0,0489 & 0,032924 & 0,876812 & 0,3816 \\
\hline
\end{tabular}

\section{3. Заключение и обсуждение}

Реформа системы коллективного права на лес является основой фрагментации лесов Китая. Благодаря природно-географическим особенностям и ресурсным различиям последствия процесса фрагментации лесных массивов становятся все более заметными. Последняя Лесная реформа также повышает уровень фрагментированности. Данные опроса показывают, что общее количество лесных участков увеличилось на $16,12 \%$, причем наибольший рост произошел в провинциях Гуанси и Ляонин, а наименьший - в провинции Хунань.

Результаты исследования показывают также, что были установлены равные права на пользование лесом; количество лесных участков на домохозяйство не увеличивается. Это свидетельствует об ограниченном влиянии последней Лесной реформы на процесс фрагментации лесов. Сравнив данные, мы видим, что горная местность имеет более значительное влияние на этот процесс, чем равнинная местность, но это влияние сдерживается пространственными ограничениями и отставанием во времени. Статистика количества и площади лесных участков и средняя площадь лесов говорят о том, что фрагментированность лесов в Китае не очень высока. Поэтому уровень жизни домохозяйств и фрагментированность лесных массивов не растут такими же темпами. Распределение лесных массивов между домохозяйствами скорее увеличивает площадь леса, принадлежащего фермерам, что увеличивает масштабы его эксплуатации. В целом эффект масштаба означает снижение себестоимости и увеличение производства при расширении эксплуатации. По этой причине мы не должны поощрять монополию на землю.

Количественный анализ показывает, что, при определенных интервалах $\mathrm{S}$-индекса, чем выше уровень фрагментированности лесных массивов, тем сложнее для фермеров инвестировать средства в лесное хозяйство. Но когда уровень фрагментированности лесов ниже 0,22 или выше 0,51 , это создаст благоприятную ситуацию для инвестиций. Та же логика применима к соотношению между инвестициями и доходами. Это означает, что уровень фрагментированности лесов и уровень инвестиций не имеют отрицательной линейной корреляции, а расширение масштабов эксплуатации и уровень инвестиции не имеют положительной линейной корреляции, что подтверждается полевыми исследованиями. Основными причинами недостаточного объема инвестиций являются недостаток капитала и рабочей силы и низкая прибыль от лесного хозяйства. Нехватка рабочей силы обусловлена крупными масштабами экс- 
плуатации и высокой заработной платой. Поэтому при текущих условиях эксплуатации должна быть соответствующая обеспеченность рабочей силой и поддержкой внешнего капитала - эти аспекты должны быть включены в программные предложения по сохранению масштабов эксплуатации лесных массивов.

Фрагментация лесных массивов имеет негативные последствия для производства древесины, но не оказывает существенного влияния на производство бамбука. Уровень инвестиций является наиболее важным фактором для производства бамбука, и, когда капитала недостаточно, чем боль- ше площадь бамбукового леса, тем ниже выход продукции с лесного участка за счет снижения в среднем объеме инвестиций. Таким образом, труд и инвестиции оказывают положительное воздействие на производство изделий из древесины и бамбука, и здесь физические инвестиции имеют наибольший эффект. Это означает также, что, после того как земля будет поделена между домохозяйствами, физические инвестиции становятся ключевым фактором, влияющим на выпуск товарной продукции, и должны быть рассмотрены в соответствующих планах для создания более эффективных стимулов для фермеров.

\section{Литература}

1. Binns B. O. The Consolidation of Fragmented Agricultural Holdings. FAO Agriculture Studies, 11. Washington DC, 1950.

2. Buek J. L. Land utilization in China. London: Oxford University Press, 1964.

3. Di S. Opinion on Forest Corporation. Forest Economics, 1994, no. 1, pp. 2-68.

4. Gao L. Discussion on Collective Forest Business Analysis. Forest Economic Problems, 2007, no. 8, pp. 376-379.

5. Jia Z. Effect of Forest Reform. Special Issue of National Forest Bureau. 2009. Available at: http://www.forestry. gov.cn/ZhuantiAction.do? Dispatch $=$ content $\&$ id $=303242 \&$ name $=$ lqgg

6. King R.L., Burton. S.R. Land Fragmentation, a Fundamental Rural Partial Problem. Progress in Human Geography, 1982, no. 6, pp. 475-494.

7. Kong F. Collective Forest Rights System: Transition, Effects and Discovery. China Environmental Science Press, 2008, no. 11, p. 104.

8. Li J., Wang F. Practice of Sweden Private Forest Operation. Forest Economics, 2003, no. 5, pp. 52-53.

9. Li Z, Yan Z. Overview of World Private Forest. China Forest Press, 2001.

10. Liu B. Discussion on Corporation and Forest Business Reform. Forestry and Society, 2000, no. 6, pp. 47-49.

11. Lu W. Research on Chinese Private Forest Business. China Environmental Science Press, 2002, no. 6, pp. 56-57.

12. Luo L., Li H. Debates on Forest Scaling Operation. Hunan Forestry, 1999, no. 5, p. 12.

13. Wadud A., White B. Farm Household Efficiency in Bangladesh: A Comparison of Stochastic Frontier and DEA Methods. Applied Economics, 2000, no. 32, pp. 1665-1673.

14. Wang J. Practice of Private Forest Cooperation in Japan. World Forestry Research, 2009, vol. 22, no. 1, pp. 1-5.

15. Song Y. Burch Jr. W. Geballe G. Liping G. New Organizational Strategy for Managing the Forests of Southeast China. The share Holding Integrated Forestry Tenure (SHIFT) System. Forest Ecology and Management, 1997, vol. 91, no. 2-3, pp. 183-194.

16. Zeng H., Nie Y., Wang J. Trend of Small Scale Forest Operation and Foreign Experience. World Forestry Research, 2009 , vol. 22 , no. 6 , pp. 19-22.

17. Zhang L., Huang J., Rozelle S. Land Policy and Land Use in China. Agricultural Policies in China, 1997. 


\title{
Сведения об авторах
}

Кун Фаньбинь - вице-президент, Академия общественных наук провинции Цзянси (г. Нанчан, KHP)

Фань Бинь - начальник Отдела научных исследований, Академия общественных наук провинции Цзянси (г. Нанчан, КНР)

Чэнь Шэньдун - научный сотрудник Отдела научных исследований, Академия общественных наук провинции Цзянси (г. Нанчан, КНР)

(C) Kong Fanbin, Fan Bin, Chen Shendong

\section{Relationship between Fragmentized Collective Forestland, Farmers Investment and Forest Commodity Output: An Analysis on Nine Provinces Farmers Survey Data in China}

Kong Fanbin - Vice President of Jiangxi Academy of Social Sciences

Fan Bin - Director of Scientific Research Department, Jiangxi Academy of Social Sciences

Chen Shendong - Researcher, Scientific Research Department, Jiangxi Academy of Social Sciences

\begin{abstract}
The purpose of this study is to quantify the relationship between fragmentized collective forestland, farmers investment and forest commodity output to examine the rationality of collective forest right reform after dispersed forestland operation. The data is based on the 2420 farmers' survey data in nine provinces of China including Fujian, Jiangxi, Hunan, Sichuan, Zhejiang, Guangxi, Henan, Shandong and Liaoning. The results show that if $\mathrm{S}$ index is used, fragmentized forestland reaches 0.41 and can be ordered (from high to low) as Zhejiang, Jiangxi, Hunan, Liaoning, Sichuan, Fujian, Guangxi and Shandong. Under certain fragmentized intervals (forestland fragmentized ratio lower than 0.22 or higher than 0.51 ), the higher the forestland fragmentized, the lower the farmers investment. The investment-output model indicates that forest block reflects the negative impacts to forest output while other variables such as labor, tangible inputs and forestland have positive impacts. When bamboo is produced, level of fragmentation has negative impacts on forestland acreage and significant positive impacts on labor used. The study implies that after the land is divided to households, physical investment is the key factor to affect the commodity output and should be considered by the related policies to increase the incentives of farmers. Based on this study, we provide some information and guidance on policy of farmers' forestland operation in large scale.
\end{abstract}

Key words: collective forest rights reform, fragmentized forestland, farmers' investment, forest commodity output.

\section{References}

1. Binns B. O. The Consolidation of Fragmented Agricultural Holdings. FAO Agriculture Studies, 11. Washington DC, 1950.

2. Buek J. L. Land utilization in China. London: Oxford University Press, 1964.

3. Di S. Opinion on Forest Corporation. Forest Economics, 1994, no. 1, pp. 2-68.

4. Gao L. Discussion on Collective Forest Business Analysis. Forest Economic Problems, 2007, no. 8, pp. 376-379.

5. Jia Z. Effect of Forest Reform. Special Issue of National Forest Bureau. 2009. Available at: http://www.forestry.gov. $\mathrm{cn} /$ ZhuantiAction.do? Dispatch $=$ content\&id=303242\&name=lqgg 
6. King R.L., Burton. S.R. Land Fragmentation, a Fundamental Rural Partial Problem. Progress in Human Geography, 1982, no. 6, pp. 475-494.

7. Kong F. Collective Forest Rights System: Transition, Effects and Discovery. China Environmental Science Press, 2008, no. 11, p. 104.

8. Li J., Wang F. Practice of Sweden Private Forest Operation. Forest Economics, 2003, no. 5, pp. 52-53.

9. Li Z, Yan Z. Overview of World Private Forest. China Forest Press, 2001.

10. Liu B. Discussion on Corporation and Forest Business Reform. Forestry and Society, 2000, no. 6, pp. 47-49.

11. Lu W. Research on Chinese Private Forest Business. China Environmental Science Press, 2002, no. 6, pp. 56-57.

12. Luo L., Li H. Debates on Forest Scaling Operation. Hunan Forestry, 1999, no. 5, p. 12.

13. Wadud A., White B. Farm Household Efficiency in Bangladesh: A Comparison of Stochastic Frontier and DEA Methods. Applied Economics, 2000, no. 32, pp. 1665-1673.

14. Wang J. Practice of Private Forest Cooperation in Japan. World Forestry Research, 2009, vol. 22, no. 1, pp. 1-5.

15. Song Y. Burch Jr. W. Geballe G. Liping G. New Organizational Strategy for Managing the Forests of Southeast China. The share Holding Integrated Forestry Tenure (SHIFT) System. Forest Ecology and Management, 1997, vol. 91, no. 2-3, pp. 183-194.

16. Zeng H., Nie Y., Wang J. Trend of Small Scale Forest Operation and Foreign Experience. World Forestry Research, 2009, vol. 22, no. 6, pp. 19-22.

17. Zhang L., Huang J., Rozelle S. Land Policy and Land Use in China. Agricultural Policies in China, 1997. 